\section{Superoxide Dismutase and Stress Tolerance of Four Tomato Cultivars}

\author{
S.M. Lutfor Rahman ${ }^{1}$ and Wayne A. Mackay ${ }^{2}$ \\ Texas A\&M Dallas, Texas Agricultural Experiment Station, Research and \\ Extension Center, 17360 Coit Road, Dallas, TX 75252-6599
}

Eiji Nawata $^{2}$ and Tetsuo Sakuratani ${ }^{3}$

Laboratory of Tropical Agriculture, Division of Environmental Science and Technology, Postgraduate School of Agriculture, Faculty of Agriculture, Kyoto University, Kitashirakawa, Oiwake-cho, Sakyoku, Kyoto 606-8502, Japan

\author{
A.S.M. Mesbah Uddin ${ }^{4}$ \\ Regional Agricultural Research Station, Soil Science Division, Bangladesh \\ Agricultural Research Institute, Hathazari, Chittagong, Bangladesh
}

\section{Bruno Quebedeaux ${ }^{3}$ \\ University of Maryland, Natural Resource Sciences and Landscape Architecture, Plant Science Building, Room 2130, College Park, MD 20742}

\section{Additional index words. Lycopersicon esculentum Mill., tomato, cultivar, water stress, leaf} water potential

\begin{abstract}
Effects of water stress on superoxide dismutase (SOD) activities, changes in protein content, leaf water potential $\left(\Psi_{l}\right)$ and growth were studied in drought-sensitive Kyokko (KK) and Ratan (RT), and drought-tolerant TM 0126 (TM) and VF-134-1-2 (VF) cultivars of tomato (Lycopersicon esculentum Mill.) in order to obtain fundamental information for breeding drought tolerant cultivars that may be adapted to water stress in many parts of the world. Growth of drought-tolerant TM and VF was greater than that of droughtsensitive KK and RT under water stress conditions. Leaf water potential $\left(\Psi_{l}\right)$ decreased by water stress treatments in all the cultivars, but the reduction was much more rapid and pronounced in KK and RT than VF and TM. $\Psi_{l}$ of stressed cultivars decreased by $30 \%$ to $40 \%$ compared to the untreated control cultivars. The initial reduction in the range of $20 \%$ to $35 \%$ was more rapid in KK and RT than TM and VF. SOD activities were increased by water stress in all cultivars. Increase of SOD activities by water stress was much more rapid and pronounced in TM and VF than in KK and RT. Leaf protein concentration was decreased by the water stress treatments in all cultivars evaluated. In KK and RT, much more rapid reductions in protein concentration were observed than in TM and VF. The regression analysis of $\Psi_{l}$ and SOD suggest the possibility to using SOD activities as an additional screening criterion for tomato drought tolerance improvement.
\end{abstract}

Superoxide dismutase (SOD;E.C. 1.15.1.1) is considered to be vital for survival and function of aerobic organisms. These metaloenzymes scavenge the superoxide radicals that are constantly formed as by-products of aerobic metabolism. In plants the photosynthetic process produces high intra-cellular concentrations of active oxygen species and reduced compounds such as NADPH (Asada and Takahashi, 1987). This process must therefore be accompanied with a protective array of enzymes and antioxidants that prevents membrane peroxidation and other types of

Received for publication 20 Sept., 2002. Accepted for publication in 3 June 2003. This research was supported by Ministry of Education, Culture, Sports, Science and Technology (MONBUSHO), Government of Japan. Use of trade names of commercial products in the publication is solely for the purpose of providing specific information and does not imply recommendation or endorsement by the U.S. Dept. of Agriculture.

${ }^{1}$ Plant physiologist.

${ }^{2}$ Associate professor.

${ }^{3}$ Professor:

${ }^{4}$ Scientific officer. injury. Oxyradicals are also formed in cellular compartments other than the chloroplast (Elstner, 1982; Halliwell, 1984); thus SODs are considered to be important components of the defense mechanisms in plants and have consequently been the focus of many research activities. In the presence of metal ions (such as iron), SOD and hydrogen peroxide can react in a Haber-Weiss reaction to form hydroxyl radicals:

$$
\mathrm{O}_{2} \cdot \cdot^{-}+\mathrm{H}_{2} \mathrm{O}_{2} \stackrel{\mathrm{Fe}^{2+}, \mathrm{Fe}^{3+}}{\rightarrow} \mathrm{O}_{2}+\cdot \mathrm{OH}+\mathrm{OH}^{-}
$$

(Haber-Weiss reaction) [1]

$2 \mathrm{O}_{2} \cdot^{-}+2 \mathrm{H}^{+} \rightarrow \mathrm{O}_{2}+\mathrm{H}_{2} \mathrm{O}_{2} \quad$ (SOD) [2]

This enzyme is unique in that its activity determines the concentrations of $\mathrm{O}_{2} .^{-}$and $\mathrm{H}_{2} \mathrm{O}_{2}$, the two Haber-Weiss reaction substrates, and it is therefore likely to play a central role in the defense mechanism for plants.

A plant response to drought stress is a complex phenomenon that appears to involve the synthesis of polyamines and a new set of proteins whose function is largely unknown (Caplan et al., 1990). Drought also reduces the availability of $\mathrm{CO}_{2}$ for photosynthesis, which can lead to the formation of reactive oxygen species from misdirecting electrons in the photo systems. Hence, mechanisms that reduce oxidative stress may play an important secondary role in drought tolerance (Bowler et al., 1992).

In tomato (Lycopersicon esculentum Mill.), cytosolic $\mathrm{Cu} / \mathrm{Zn}$ SOD is reduced by drought while the chloroplastic $\mathrm{Cu} / \mathrm{Zn}$ SOD remained largely unaffected (Gianinetti et al., 1993). Glutathione reductase activity increased in drought-stressed wheat (Triticum aestivum L.) and cotton (Gossypium hirsutum L.) and it was proposed that as well as removing $\mathrm{H}_{2} \mathrm{O}_{2}$, this increase may convert NADP that can accept electrons from Ferredoxin to an available form, and thereby minimize superoxide formation. In drought-tolerant Hordeum species, levels of glutathione reductase and ascorbate peroxidase increased, but SOD activity was not examined (Smirnoff and Colombe, 1988). Droughtstressed cotton was found to be resistant to a subsequent challenge of paraquat (Burke et al., 1985), which may indicate the existence of a common protective mechanism against these stresses.

Drought-induced changes in lipid peroxidation and the activities of SOD and catalase were compared in two mosses, the drought-tolerant Tortula ruralis and the drought-sensitive Cratoneuron filicinum (Dhinsa and Motowe, 1981). During stress treatment the droughttolerant moss showed lower levels of lipid peroxidation, together with increased levels of both enzymes; the opposite occurred in the drought-sensitive moss. Drought tolerant and intolerant maize inbred were analyzed by Malan et al. (1990), and tolerance to drought was found to correlate with $\mathrm{Cu} / \mathrm{Zn}$ SOD and glutathione reductase activities.

Therefore, increased SOD activities may be directly related to drought tolerance in tomato. In addition, increased SOD activities may be a useful criterion for drought tolerance if stable relationships with tolerance can be identified. Our objective in this study was to analyze the relationship between drought tolerance and SOD activities in four tomato cultivars and to determine if SOD activity is a worthwhile screening criterion for drought tolerance in tomato.

\section{Materials and Methods}

Plant materials and growing conditions. Four cultivars of tomato were selected for this study. TM0126 (TM) and VF 134-1-2 (VF) are drought-tolerant and Kyokko (KK) and Ratan (RT) are drought-sensitive cultivars. Seeds of the four cultivars were disinfested with the fungicide Benlate(Dupont Ltd., Wilmington, Del.) for $2 \mathrm{~min}$, soaked in distilled water for $24 \mathrm{~h}$, and sown in a plastic container of vermiculite on 4 Apr. 1997. Benlate was also applied to plants every 7 to $10 \mathrm{~d}$ to prevent disease infections. Seedlings were grown in a phytotron under 25 ${ }^{\circ} \mathrm{C}$ day $/ 20{ }^{\circ} \mathrm{C}$ night temperature regime. Ten days after sowing, the plants were transferred to plastic pots (9 $\mathrm{cm}$ diameter) filled with 1 perlite : 2 sand : 1 peat (by volume) and placed 
under $23^{\circ} \mathrm{C}$ day $/ 18^{\circ} \mathrm{C}$ night regime. On $21 \mathrm{Apr}$., plants were retransplanted to $30-\mathrm{cm}$-diameter pots filled with 1 perlite : 2 sand $: 1$ peat (by volume) and placed in a plastic greenhouse at Kyoto Univ., Japan under natural temperature conditions (daily maximum temperatures ranging from 26.3 to $35.7^{\circ} \mathrm{C}$ and daily minimum temperature 15.4 to $25.6^{\circ} \mathrm{C}$ ). On 1 May, water stress treatments were initiated when plants had four to five nodes/plant $(\approx 25-30 \mathrm{~cm}$ height $)$ in all cultivars. The plants were separated into two groups. Half of the plants received no water, and the remaining plants were well watered. Half strength Enshi nutrient solutions (Yamasaki, 1982) for macro elements and Arnon nutrient solution (Arnon and Hoagland, 1940) for microelements were applied three times a week except during the treatment period. During the treatment period, a slow release granular fertilizer containing $14 \%$ of $\mathrm{N}, 5.28 \%$ of $\mathrm{P}$ and $9.96 \%$ of $\mathrm{K}$ was applied to each pot. Plants were sampled at $0,3,6$, and $9 \mathrm{~d}$ after the onset of the water treatments (DAT). Samples were also collected 2 and $4 \mathrm{~d}$ after rewatering (DAW). For dry weight measurements, the individual plants were harvested and oven dried at $80{ }^{\circ} \mathrm{C}$ for 96 $\mathrm{h}$ at the end of the experiment.

Experimental design. A split-plot design was used with four replications. The main plot consisted of the water stress treatments (stress vs. no stress), and the subplot factor was tomato cultivar (four tomato cultivars). Forty tomato plants were used per cultivar per replication. Of the 40 plants, 20 plants were used for the control treatment and 20 plants were used for the water stress treatment. Four plants per cultivar/treatment for each combination replication were randomly chosen to collect root and shoot dry weight data, six plants per cultivar per treatment were randomly chosen for SOD analysis, and four plants were randomly chosen for leaf water potential measurements. There were six unused plants in each group. Plants were spaced $0.2 \mathrm{~m}$ within the row and $0.4 \mathrm{~m}$ between rows.

Relative performance measurement. As a mean for comparing the relative performance among cultivars, the following values were calculated for the measured traits.

Relative performance $(\mathrm{RP})=$

(performance under stress $\div$

performance under control condition) $\times 100$

Days of water withholding period ( $D W W$ ) measurement. Before initiating the treatment, all pots were saturated with $500 \mathrm{~mL}$ of water per pot in order to create equal moisture conditions in all pots. Water was then withheld until visible wilting symptoms persisted throughout the night in the water stressed plants. Plants were then rewatered and the day of water withholding period (DWW) was recorded for each cultivar. After re-watering the recovery of the cultivars was carefully observed and recorded.

Enzyme extracts, enzyme assay and determination of protein concentration. Our preliminary laboratory studies showed that there were little diurnal changes in SOD activities and based on this observation, leaf samples were collected at 10 AM at 0, 3, 6, and 9 DAT and 2 and 4 DAW. The first fully expanded leaf below the shoot apex was excised, weighed $(\approx 0.5 \mathrm{~g}$ fresh weight), and immediately placed in liquid nitrogen $\left(\mathrm{N}_{2}\right)$, lyophilized and stored at $-20^{\circ} \mathrm{C}$ for SOD activity analysis. The fresh leaf samples $(500 \mathrm{mg})$ were homogenized in $1 \mathrm{~mL}$ of $50 \mathrm{~mm}$ potassium phosphate and 1 mmEDTA ( $\mathrm{pH} 7.5$ ) buffer. The homogenates were filtered through four layers of cheesecloth and then centrifuged at $4{ }^{\circ} \mathrm{C}$ for $15 \mathrm{~min}$ at $9400 g_{\mathrm{n}}$. The supernatants were collected and used for SOD assay and protein content after an appropriate dilution.

Leaf superoxide dismutase activity (SOD) was analyzed according to the procedure of Beyer and Fridovich (1987). One enzyme unit of SOD activity was defined as the amount of enzyme required to cause $50 \%$ inhibition of nitro blue tetrazolium (NBT, Wako Pure Chemical Industries, Japan) reduction measured at 560 $\mathrm{nm}$ on a spectrophotometer (Hitachi U-2000). The specific activity of SOD was expressed as unit per mg protein, as follows,

\section{SOD $($ unit $/ \mathrm{mg}$ protein $)=$ \\ $1 /\left[\right.$ protein concentration $\left(\mu \mathrm{g} \cdot \mu \mathrm{L}^{-1}\right) \times$ sample $20 \mu \mathrm{L} /$ point of $50 \%$ inhibition rate of $\left.\mathrm{NBT} \times 10^{-3}\right]$.}

Protein content was determined according to Bradford (1976) using bovine serum albumin (BSA) as a standard.

Leafwaterpotentialmeasurement $\left(\Psi_{l}\right)$. Leaf water potential $\left(\Psi_{t}\right)$ was measured at midday on $0,3,6$, and 9 DAT and 2 and 4 DAW by the pressure-bomb technique (Tyree and Hammel, 1972), using the uppermost fully expanded leaf (three to four nodes from the shoot apex). Four leaves from each experimental unit were pooled. Leaf stomatal conductances were also measured but the data are not shown here.

Statistical analysis. All data were subjected to analysis of variance (ANOVA) computed by Excel (Microsoft Corp., Redmond, Wash.) and the transformed means were separated by Student's $t$ test. Regression analyses were performed by CA-Cricket Graph (ComputerAssociates, Islandia, N.Y.) program in a Macintosh computer. Regression equations were selected on the best and most significant $(P \leq 0.05)$ regression parameters with highest coefficient of determination $\left(r^{2}\right)$.

\section{Results}

Dry weight of root, shoot and days of water withholding periodeffects. Effects of water stress on root and shoot dry weight and days of water withholding period (DWW) are shown in Table 1. The DWW was significantly longer $(3 \mathrm{~d})$ in

Table 1. Effects of water stress on root and shoot dry weight and days of water withholding period.

\begin{tabular}{|c|c|c|c|c|c|c|c|}
\hline \multirow[b]{2}{*}{ Cultivars } & \multicolumn{3}{|c|}{ Root dry wt (g) } & \multicolumn{3}{|c|}{ Shoot dry wt (g) } & \multirow[b]{2}{*}{$\mathrm{DWW}^{\mathrm{y}}$} \\
\hline & Control & Stress & $\operatorname{RP}^{\mathrm{z}}(\%)$ & Control & Stress & $\mathrm{RP}(\%)$ & \\
\hline Kyokko & $10.9 \mathrm{a}^{\mathrm{x}}$ & $7.3 \mathrm{~b}$ & 63 & $17.9 \mathrm{a}$ & $12.9 \mathrm{~b}$ & 71 & $10.0 \mathrm{~B}$ \\
\hline Ratan & $6.9 \mathrm{a}$ & $3.9 \mathrm{~b}$ & 49 & $10.9 \mathrm{a}$ & $6.8 \mathrm{~b}$ & 58 & $9.0 \mathrm{~B}$ \\
\hline TM-0126 & $12.2 \mathrm{a}$ & $9.8 \mathrm{~b}$ & 79 & $17.1 \mathrm{a}$ & $14.5 \mathrm{~b}$ & 84 & $13.2 \mathrm{~A}$ \\
\hline VF134-1-2 & $10.1 \mathrm{a}$ & $7.5 \mathrm{~b}$ & 71 & $15.7 \mathrm{a}$ & $12.7 \mathrm{~b}$ & 79 & $12.7 \mathrm{~A}$ \\
\hline
\end{tabular}

${ }^{2} \mathrm{RP}=$ relative performance

${ }^{y} \mathrm{DWW}=$ days of water withholding period

${ }^{x}$ Different letters significantly different at $P<0.05$. Small letters significantly different between control and stress treatment. Capital letters significantly different among cultivars.
TM and VF than in RT and KK. Root dry matter significantly decreased by the treatment in all the cultivars. Reduction by water stress was more pronounced in KK and RT than in TM and VF. Similar trends were observed for the effects of water stress on shoot dry weight. effects of water stress on leaf water potential $\left(\Psi_{t}\right)$ are shown in Fig. 1. $\Psi$, was decreased by $30 \%$ to $40 \%$ compared to the untreated control in cultivars tested. The initial reduction was in the range of $20 \%$ to $35 \%$ and was more rapid in KK and RT than in TM and VF. After re-watering, $\Psi_{l}$ of stressed plants increased more rapidly in TM and VF than in KK and RT. In KK and that of the control at 4 DAW.

Superoxide dismutase (SOD) activity. The effects of water stress on SOD activity are shown in Fig. 2. The SOD activity was increased by water stress in all four cultivars. The increase of SOD activity by water stress was more rapid and pronounced in TM and VF than in KK and RT. After re-watering, SOD activity quickly declined to the control level in all cultivars for stressed plants at 2 DAW except RT, which reached control level at 4 DAW. In the nonstressed control plants, TM and VF had higher SOD activities.

Effects of leaf protein. The effects of water stress on leaf protein concentration of tomato cultivars are shown in Fig. 3. Protein concentration was decreased by the water stress treatments in all the cultivars. A more rapid reduction was observed in KK and RT, than in TM and VF. The KK and RT reached their minimum value of protein content earlier than TM and VF. After re-watering, the protein content increased more rapidly in TM and VF. At 4 DAW, leaf protein contents of stressed plants in TM and VF nearly approached the control levels, but in KK and RT, those of stressed plants remain much lower than those of control plants.

Regression of SOD activities with changes in leaf water potential $\left(\Psi_{1}\right)$. Fig. 4 shows the regression of SOD activities with changes in $\Psi_{l}$ in each cultivar. The equations were similar for KK and RT and also for TM and VF. Both intercept and slope were significantly different when tolerant cultivars (TM and VF) were compared to sensitive cultivars (KK and RT).

\section{Discussion}

As shown in dry matter production, days of water withholding period (Table 1) and changes of leaf water potential (Fig.1), drought-tolerant cultivars (TM and VF) clearly
Leaf water potential response $\left(\Psi_{t}\right)$. The $\mathrm{RT}, \Psi_{l}$ in stressed plants was much lower than 

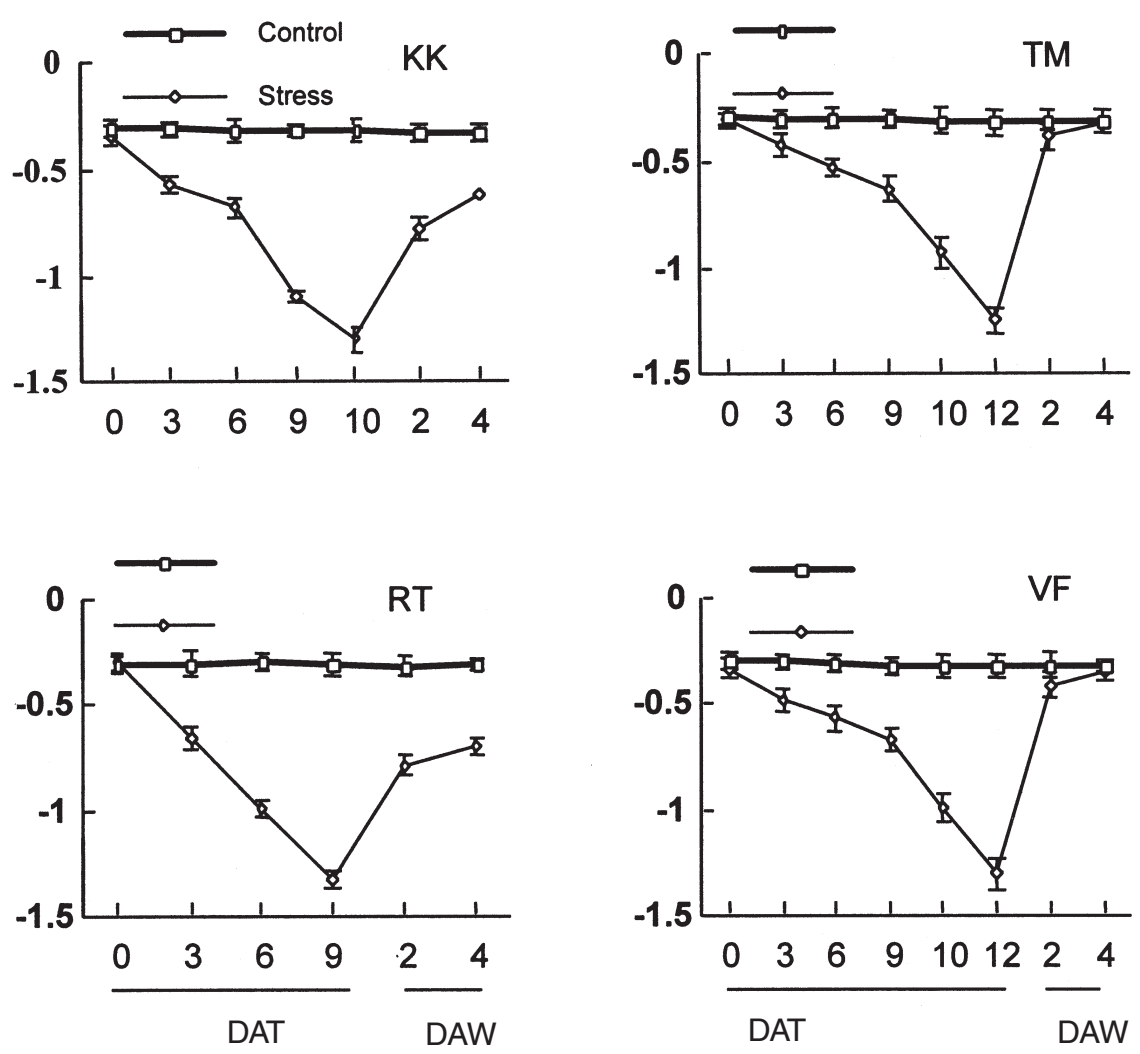

Fig. 1. Effects of water stress on leaf water potential $\left(\Psi_{l}\right)$ in four tomato cultivars. DAT and DAW represent days after treatment and days after re-watering, respectively. Bar indicates standard error $( \pm \mathrm{SE})$. KK = Kyokko, RT = Ratan, TM = TM-0126, and VF = VF134-1-2.
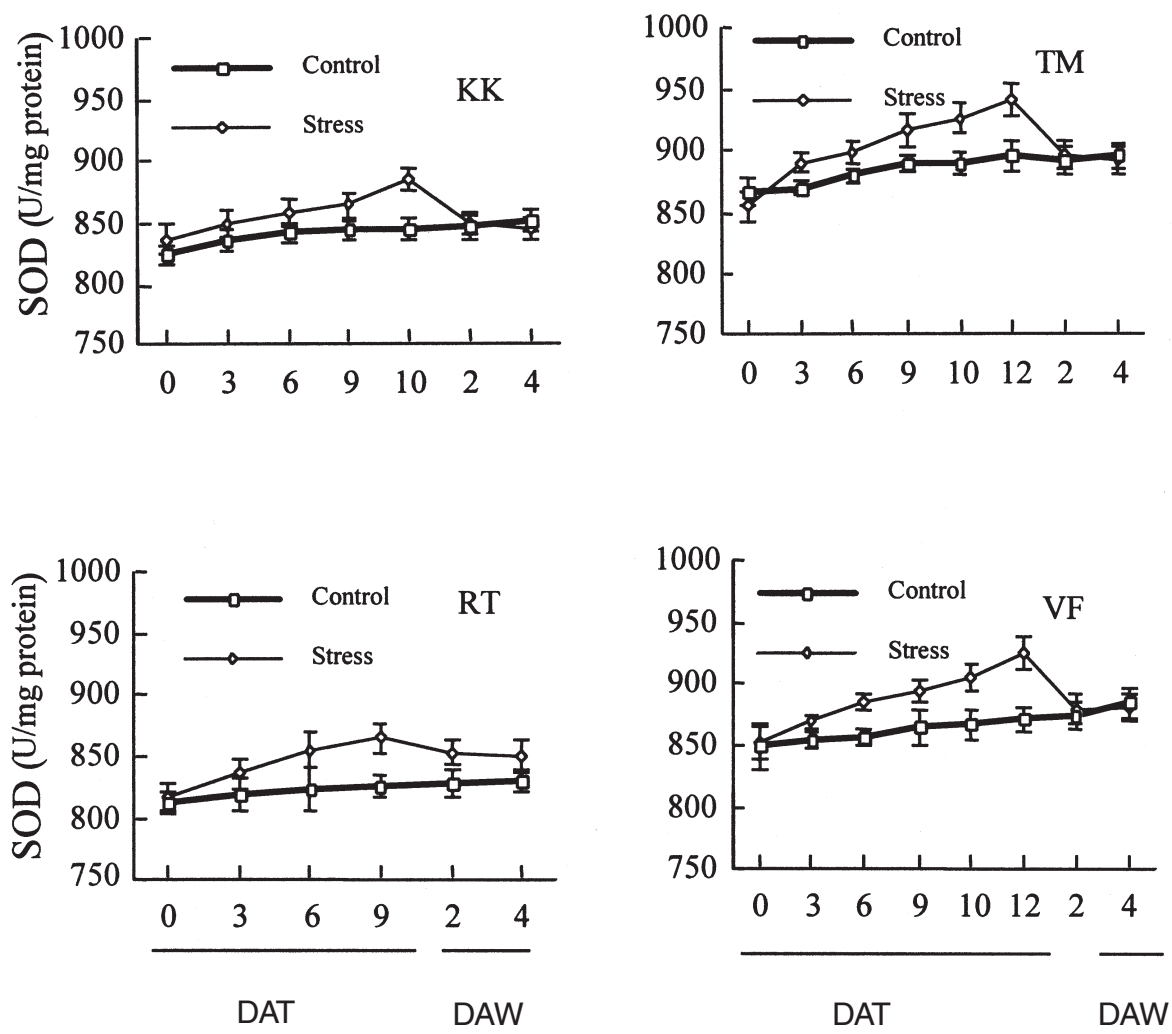

showed improved growth performance under water stress conditions than drought-sensitive cultivars (KK and RT).

Total leaf protein contents were reduced by water stress, but the reduction was more pronounced in drought-sensitive KK and RT than in drought-tolerant TM and VF (Fig. 3). Chen and Tabaeizadeh (1992) demonstrated that water stress promoted syntheses of the stress-specific proteins and repressed the preexisting protein syntheses in tomato. Although the syntheses of new proteins specific to water stress conditions may have occurred in this experiment, the total protein syntheses are reduced by water stress, probably because of the suppression of energy supply due to reduced photosynthesis and overall adverse effects of stress on biochemical processes. The improved performance of drought-tolerant cultivars under water stress conditions may be related to the ability to minimize the reduction in protein syntheses.

Although total leaf protein syntheses were suppressed by water stress, SOD activities were increased by the stress (Fig. 2). Some of the adverse effects of water stress on plant growth are known to be mediated by the production and accumulation of toxic, reactive oxygen intermediates such as superoxide radicals (Asada and Takahashi, 1987). SOD may act as a scavenging system to protect cells against oxygen radicals that catalyze the reduction of superoxide radicals, and their activities are increased by water stress in many plants (Asada and Takahashi, 1987). In tomato, the increase in SOD activities by water stress were clearly observed in this study and specific cultivar difference were found. In drought-tolerant TM and VF, the increase of SOD activities by water stress was more rapid and pronounced than in drought-sensitive KK and RT. The regression analysis suggests that the slope of the regression equation of drought-tolerant cultivars was much larger than that of droughtsensitive cultivars (Fig. 4), indicating that drought-tolerant cultivars responded to smaller decreases in leaf water potential and increased SOD activities than drought-sensitive cultivars. This suggests that SOD activity is considered to have an important role in drought-tolerant tomato cultivars.

Regression analysis also showed that the intercept of the regression equation was much larger in drought-tolerant cultivars than in drought-sensitive cultivars. This indicates that SOD activities of non-stressed plants were higher in drought-tolerant cultivars than in sensitive cultivars. Our studies suggest that differences in SOD activities may be a useful screening criterion for drought tolerance and it may be possible to select drought-tolerant tomato cultivars on the basis of SOD activities. Further detailed genetic studies on this specific point are necessary.

Fig. 2. Effects of water stress on superxide dismutase (Unit.mg protein) activity of four tomato cultivars. DAT and DAW represent days after treatment and days after rewatering, respectively. Bar indicates standard error $( \pm \mathrm{SE}) . \mathrm{KK}=$ Kyokko, $\mathrm{RT}=\mathrm{Ratan}, \mathrm{TM}=\mathrm{TM}-0126$, and $\mathrm{VF}=1134-1-2$. 

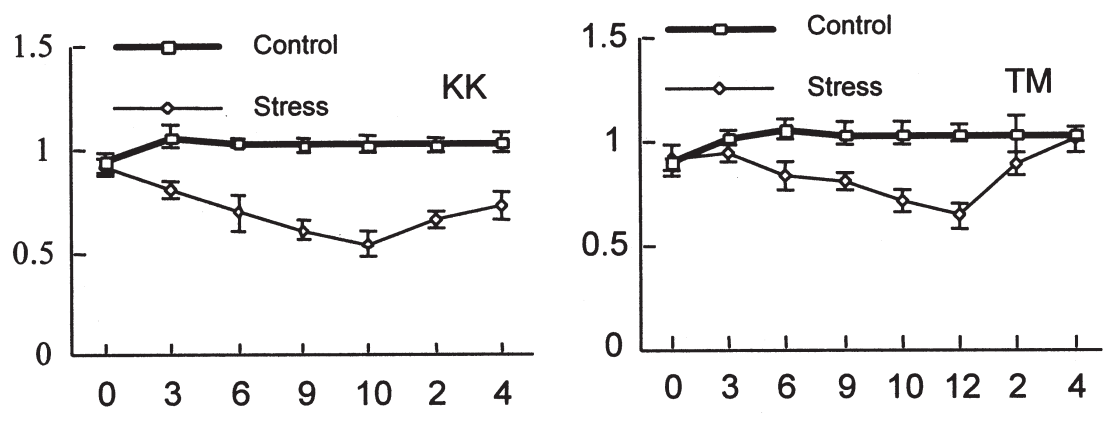

Literature Cited tion in artificial culture solutions and in soils with special reference to factors influencing yields and absorption of inorganic nutrients. Soil Sci. 50:463-485.

Asada, K. and M. Takahashi. 1987. Production and scavenging of active oxygen in photosynthesis, p. 227-287. In: D.J. Kyle, C.B. Osmond, and C.J. Arntzen (eds.). Photo inhibition. Elsevier, Amsterdam.

Beyer, Jr., W.F. and I. Fridovich. 1987. Assaying for super oxide dismutase activity: Some large consequences of minor changes in conditions. Annal. Biochem. 161:559-566.
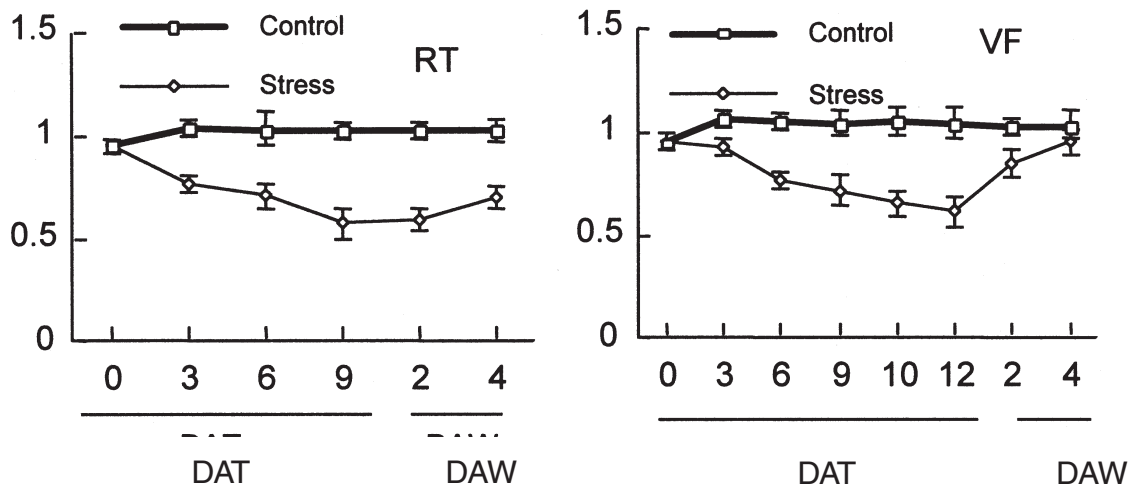

Bowler, C., M. Van Montagu, and D. Inze. 1992. Super oxide dismutase and stress tolerance. Annu. Rev. Plant Physiol. Plant Mol. Biol. 43:83-116.

Bradford, M.M. 1976. A rapid and sensitive method for the quantitation of microgram quantities of protein using the principle of protein-dye binding. Ann. Biochem. 72:248-254.

Burke, J.J., P.E. Gamble, J.L. Hatfield, and J.E. Quisenberry. 1985. Plant morphological and biochemical responses to field water deficits. I. Responses of glutathione reductase activity and paraquat sensitivity. Plant Physiol. 79:415-419.

Caplan, A., B. Clases, R. Dekeyser, and M. Van Montagu. 1990. Salinity and drought stress in rice, p. 391-402. In: R.S. Sangwan, B.S. Sangwan-Norreel (eds.). The impact of biotechnology in agriculture (Current plant science and biotechnology in agriculture, vol. 8.). Kluwer Academic, Dordrecht, the Netherlands.

g. 3. Effects of water stress on leaf protein concentration of four tomato cultivars. DAT and DAW represent days after treatment and days after re-watering, respectively. Bar indicates standard erro $( \pm \mathrm{SE}) . \mathrm{KK}=$ Kyokko, RT = Ratan, TM = TM-0126, VF = VF134-1-2.

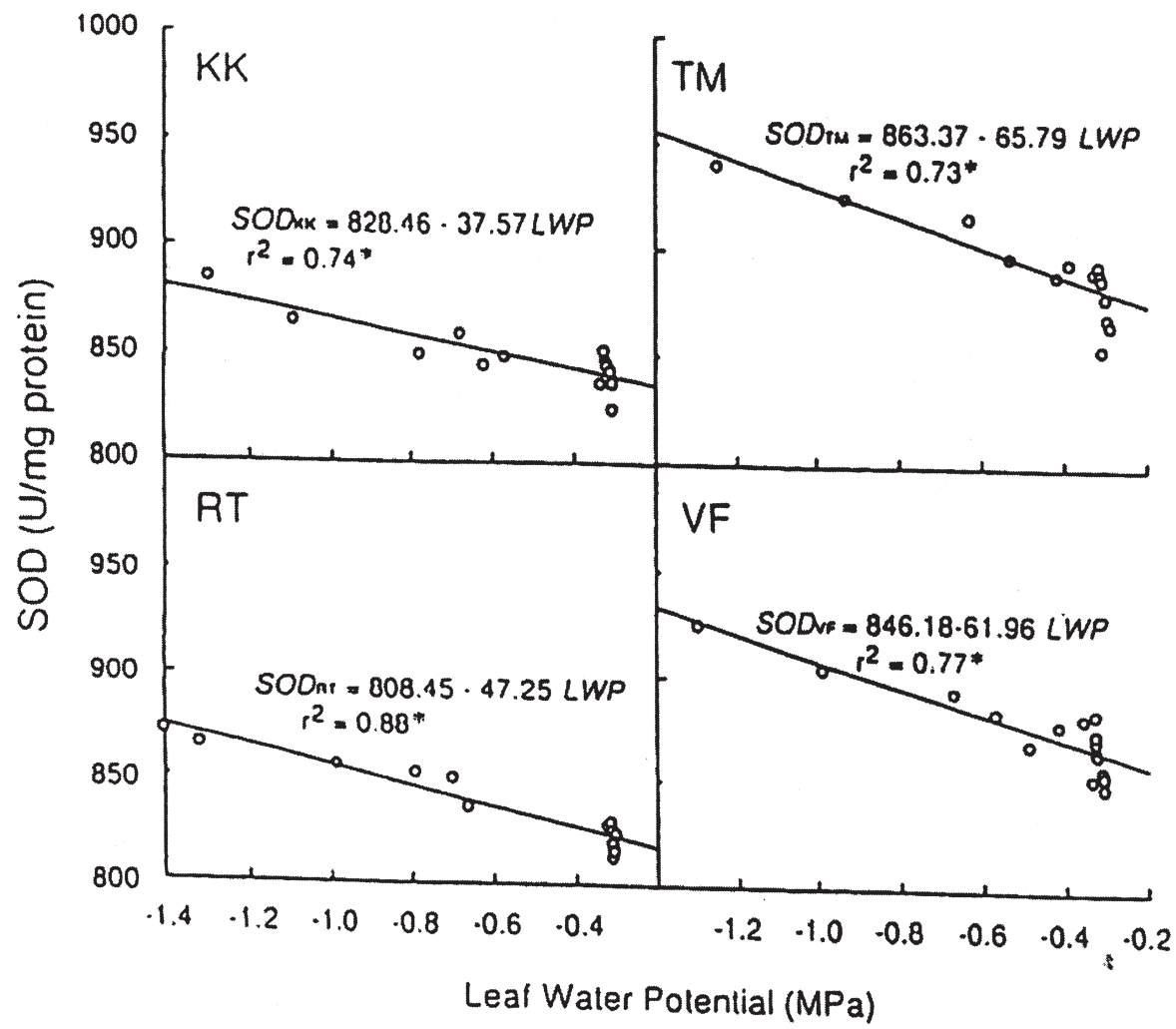

Chen, R.D. and Z. Tabaeizadeh, 1992. Alteration of gene expression tomato plants (Lycopersicon esculentum Mill.) by drought and salt stress. Genome 35:385-391.

Dhinsa, R.S. and W. Motowe. 1981. Drought tolerance in two mosses: correlation with enzymatic defense against lipid peroxidation. J. Expt. Bot. 32:79-91.

Elstner, E.F. 1982. Oxygen activation and oxygen toxicity. Annu. Rev. Plant Physiol. 33:73-96.

Gianinetti, A., C. Lorenzoni and A. Marocco. 1993. Changes in super oxide dismutase and catalase activities in response to low temperature in tomato mutants. Plant Physiol. 59:309-314.

Halliwell, B. 1984. Toxic effects of oxygen on plant tissues, p. 180-206. In: B. Halliwell (eds.). Chloroplast metabolism. The structure and function of chloroplasts in green leaf cells. Clarendon Press, Oxford, U.K.

Malan, C., M. M. Greyling, and J. Gressel. 1990. Correlation between $\mathrm{Cu}, \mathrm{Zn}$ superoxide dismutase and glutathione reductase and environmental and xenobiotic stress tolerance in maize inbreed. Plant Sci. 69:157-166.

Smirnoff, N. and S.V.Colombe. 1988. Drought influences the activity of enzymes of the chloroplast hydrogen peroxide scavenging system. J. Expt. Bot. 39:1097-1108.

Tyree, M.T. and H.T. Hammel. 1972. The measurement of the turgor pressure and the water relation of plants by pressure bomb technique. J. Exp. Bot. 23: 267-282.

Yamasaki, K. 1982. A review on solution culture (in Japanese). Hakuyusha (Tokyo). p. 107.

Fig 4. Correlation between leaf water potential and superoxide dismutase (SOD) activity of tomato under water stress. Asterisks indicate statistical significance at $P<0.05 . \mathrm{KK}=$ Kyokko, RT $=$ Ratan, TM $=\mathrm{TM}-0126$, and $\mathrm{VF}=\mathrm{VF} 134-1-2$. 